\title{
RESPOSTA DA SOJA E DO EUCALIPTO AO AUMENTO DA DENSIDADE DO SOLO E A DOSES DE FÓSFORO(1)
}

\author{
Marco Aurélio Vitorino Ribeiro ${ }^{(2)}$, Roberto Ferreira Novais ${ }^{(3)}$, \\ Valdemar Faquin $^{(2)}$, Mozart Martins Ferreira ${ }^{(2)}$, Antônio Eduardo \\ Furtini Neto $^{(2)}$, José Maria de Lima ${ }^{(2)} \&$ Ecila Mercês de \\ Albuquerque Villani ${ }^{(4)}$
}

\begin{abstract}
RESUMO
O uso agrícola e o manejo de solos de Cerrado frequentemente causam sua compactação, reduzindo sua porosidade e disponibilidade de água e nutrientes, com efeito negativo sobre o crescimento e o desenvolvimento das culturas. $O$ presente trabalho teve por objetivo avaliar os efeitos da densidade do solo e de doses de P no crescimento da soja e do eucalipto em solos com diferentes texturas: um Latossolo Vermelho (LV) muito argiloso e outro Latossolo Vermelho-Amarelo (LVA) textura média. Em vasos plásticos de 1,8 $\mathrm{L}$, com 1,6 $\mathrm{dm}^{3}$ de solo, foram testadas, para o LV, as densidades de $0,90,1,10$ e $1,30 \mathrm{~kg} \mathrm{dm}^{-3}$ e as doses de 0,100 , 200,400 e $800 \mathrm{mg} \mathrm{dm}^{-3}$ de $\mathrm{P}$, e para o LVA, as densidades de 1,30, 1,50 e 1,70 kg dm $\mathrm{dm}^{-3}$ e as doses de $0,75,150,300$ e $600 \mathrm{mg} \mathrm{dm}^{-3}$ de P. As plantas de soja e de eucalipto foram colhidas 40 e 80 dias após a semeadura, respectivamente. Foram avaliadas: matéria seca da parte aérea (MSPA) e de raízes (MSR), acúmulo de P na MSPA (PPA) e MSR (P-R), nas duas espécies, e altura do eucalipto. Os resultados mostraram que o aumento da densidade do solo influenciou negativamente no crescimento da soja e do eucalipto, especialmente no solo LV e nas maiores doses de P; a resposta das plantas às doses de $\mathrm{P}$ aplicadas foi menor com o aumento da densidade do solo; e o aumento da densidade foi mais prejudicial ao crescimento do eucalipto-espécie mais eficiente na recuperação do $\mathrm{P}$ aplicado aos solos. De modo geral, o efeito negativo do aumento da densidade dos solos sobre a produção de MSPA das espécies, nas doses menores de $\mathrm{P}$, é compensado quando as maiores doses de $\mathrm{P}$ são aplicadas.
\end{abstract}

Termos de indexação: acúmulo de $\mathrm{P}$, compactação, degradação do solo, difusão.

\footnotetext{
(1) Parte da Tese de Doutorado do primeiro autor apresentada à Universidade Federal de Lavras - UFLA. Recebido para publicação em maio de 2009 e aprovado em maio de 2010.

(2) Professor do Departamento de Solos, Universidade Federal de Lavras - UFLA. Caixa Postal 37, CEP 37200-000 Lavras (MG). E-mails: marcoavribeiro@ufla.br; vafaquim@ufla.br; afurtini@ufla.br; mozartmf@ufla.br; jmlima@ufla.br

${ }^{(3)}$ Professor do Departamento de Solos da Universidade Federal de Viçosa - UFV. Av. P.H. Rolfs s/n, CEP 36570-000 Viçosa (MG). E-mail: rfnovais@ufv.br

(4) Engenheira-Agrônoma, Pós-Doutoranda do Departamento de Solos, UFV. Bolsista da FAPEMIG. E-mail: ecilavillani@yahoo.com.br
} 


\title{
SUMMARY: SOYBEAN AND EUCALYPTUS RESPONSE TO INCREASED SOIL DENSITY AND PHOSPHORUS DOSES
}

\begin{abstract}
Agriculture and soil management in the Cerrado can cause soil compaction, resulting in decreased porosity and water and nutrient availability, with a negative impact on plant growth and development. The objective of this study was to evaluate the effect of soil density and phosphorus doses $(P)$ on soybean and eucalyptus grown in two Cerrado oxisols with different texture: one (LV) with $610 \mathrm{~g} \mathrm{~kg}^{-1}$ clay and the other (LVA), with $190 \mathrm{~g} \mathrm{~kg}^{-1}$ clay. Three soil densities (0. 90, 1. 10 and 1. $\left.30 \mathrm{Mg} \mathrm{m}^{-3}\right)$ and five P doses (0, 100, 200, 400, and $800 \mathrm{mg} \mathrm{dm}^{-3}$ ) were used for $L V$; for $L V A$, soil densities were 1. 30, 1. 50 and $1.70 \mathrm{~kg} \mathrm{dm}^{-3}$ and P doses 0, 75, 150,300 , and $600 \mathrm{mg} \mathrm{dm}^{-3}$. Soybean plants were harvested 40 and eucalyptus plants 80 days after sowing. The dry matter and P content were evaluated in shoots and roots of both species. Plant height of eucalyptus was also evaluated. The results showed that: (a) increasing soil density decreased the growth of both species, particularly in LV; (b) plant response to P decreased with increasing soil density; (c) eucalyptus was more affected by increased soil density but absorbed the applied P more efficiently than soybean. In general, the negative effect of increased soil density on plant dry matter, for both species, at the lowest $P$ doses, was compensated when the highest $P$ doses were applied.
\end{abstract}

Index terms: phosphorus accumulation, compaction, soil degradation, diffusion.

\section{INTRODUÇÃO}

Em decorrência do uso agrícola e do manejo aplicados a solos de Cerrado, nota-se, frequentemente, melhoria nas propriedades químicas, enquanto as propriedades físicas, como a estrutura e as características dela decorrentes, tendem a deteriorarse. A compactação do solo tem sido a principal alteração observada (Carvalho Júnior et al., 1998).

A formação da camada compactada é atribuída ao uso excessivo de máquinas, implementos agrícolas e preparo do solo, o que favorece o aumento da desagregação, facilitando a eluviação de argila e formação de camada compactada (Flowers \& Lal, 1998). De acordo com Tavares et al. (2001), a compactação reduz a porosidade do solo, a continuidade dos poros e a disponibilidade de água e nutrientes, reduzindo também o crescimento e o desenvolvimento radicular das culturas. Os efeitos da compactação do solo sobre o crescimento radicular de diversas culturas têm sido relatados devido às modificações morfológicas que ocorrem, como: decréscimo na divisão celular no meristema e aumento no diâmetro da raiz, resultante do aumento na espessura do córtex, reduzindo o volume de solo explorado pelas raízes e a absorção de água e nutrientes (Borges et al., 1986, 1987; Rosolem et al., 1994; Foloni et al., 2003; Freddi et al., 2007).

Menores respostas às adubações têm sido observadas em solos que apresentam comprometimento nas suas propriedades físicas, em que o aumento da densidade do solo leva ao aumento da adsorção de $\mathrm{P}$ e à redução do seu fluxo difusivo (difusão). Segundo Novais \& Smyth (1999), a compactação resultaria, entre outros fatores, no aumento da viscosidade da água e na interação de íons de fosfato com superfícies dos coloides ao longo de sua trajetória de difusão. Isso implicaria a necessidade de maiores doses de $\mathrm{P}$, a fim de aumentar a saturação por fosfato nessas superfícies adsorventes e possibilitar a manutenção do fluxo difusivo em níveis mais adequados, em termos de demanda da planta.

O efeito do conteúdo de água do solo sobre a difusão de $\mathrm{P}$ foi estudado por Ruiz et al. (1988) em um Latossolo Vermelho-Amarelo textura média, cultivado com soja. Os resultados mostraram que, mesmo para uma dose elevada de $\mathrm{P}$ (240 $\left.\mathrm{mg} \mathrm{dm}^{-3}\right)$, o fluxo xilemático diminuiu mais de 300 vezes quando o conteúdo de água a - $0,01 \mathrm{MPa}$ reduziu para aquele correspondente a $-0,30 \mathrm{MPa}$. Nesse mesmo trabalho, verificou-se que o acúmulo de $\mathrm{P}$ no exsudato xilemático, para os tratamentos de potencial matricial de -0,04 e - $0,3 \mathrm{MPa}$, estabilizou-se a partir de $60 \mathrm{mg} \mathrm{dm}^{-3}$, com pequena resposta às doses crescentes de $\mathrm{P}$. Por outro lado, os tratamentos referentes ao potencial matricial de $-0,01 \mathrm{MPa}$ mostraram incremento pronunciado do conteúdo de $\mathrm{P}$ tanto em relação aos tratamentos com menor disponibilidade de água quanto às aplicações de maiores doses do nutriente.

Associando-se textura e água no solo, para um mesmo conteúdo volumétrico, os solos argilosos, com menor fator de impedância e maior interação íoncoloide, terão menor difusão (Nye, 1979). Villani et al. (1993), estudando a difusão de $\mathrm{P}$ em solos com diferentes texturas e níveis de umidade, observaram que no solo argiloso (LV), mesmo com doses de $\mathrm{P}$ maiores do que aquelas testadas no LVm (com menor capacidade de adsorção de P), a difusão foi, para as condições de umidade a -0,01 MPa, de duas a três vezes maior no LVm. Esses autores verificaram que, enquanto a difusão aumenta $28 \%$ no LV com a 
duplicação da dose de $\mathrm{P}$, no LVm esse acréscimo foi de $81 \%$. Concluiu-se que, nos solos argilosos mais intemperizados, pequenas reduções na disponibilidade de água terão maior efeito na difusão de $\mathrm{P}$ do que naqueles mais arenosos.

O objetivo do presente trabalho foi avaliar os efeitos da densidade do solo (compactação) e de doses de $\mathrm{P}$, em dois Latossolos com diferentes texturas, no crescimento e conteúdo de $\mathrm{P}$ em plantas de soja e de eucalipto.

\section{MATERIAL E MÉTODOS}

Dois experimentos foram conduzidos em casa de vegetação do Departamento de Solos da Universidade Federal de Viçosa, Viçosa, MG. No primeiro cultivouse soja [Glycine $\max (\mathrm{L}$.) Merrill variedade Tropical] e, no segundo, eucalipto (Eucalyptus grandis), em amostras de dois solos sob vegetação de Cerrado, classificados como Latossolo Vermelho (LV) textura argilosa, de Sete Lagoas - MG, e Latossolo VermelhoAmarelo textura média (LVA), de Lassance - MG. Amostras dos solos foram coletadas na profundidade de 0 a $20 \mathrm{~cm}$, secas ao ar, passadas em peneira de malha de $4 \mathrm{~mm}$, para obtenção de terra fina seca ao ar (TFSA), e submetidas à caracterização física e química de acordo com Embrapa (1997) (Quadro 1).

Em ambos os experimentos foi utilizado o arranjo fatorial $3 \times 5+3 \times 5$ (três densidades de solo e cinco

Quadro 1. Características químicas e físicas do Latossolo Vermelho (LV) e do Latossolo Vermelho-Amarelo (LVA) utilizados nos experimentos

\begin{tabular}{|c|c|c|}
\hline Característica & $\mathbf{L V}$ & LVA \\
\hline pH em água $(1: 2,5)$ & 4,5 & 4,3 \\
\hline $\mathrm{P}\left(\mathrm{mg} \mathrm{dm} \mathrm{m}^{-3}\right)^{(1)}$ & 1,0 & 1,0 \\
\hline $\mathrm{K}(\mathrm{mg} \mathrm{dm}-3)^{(1)}$ & 70 & 14 \\
\hline $\mathrm{Ca}^{2+}\left(\mathrm{cmol}_{\mathrm{c}} \mathrm{dm}^{-3}\right)^{(2)}$ & 0,15 & 0,00 \\
\hline $\mathrm{Mg}^{2+}\left(\mathrm{cmol}_{\mathrm{c}} \mathrm{dm}^{-3}\right)^{(2)}$ & 0,17 & 0,00 \\
\hline $\mathrm{Al}^{3+}\left(\mathrm{cmol}_{\mathrm{c}} \mathrm{dm}^{-3}\right)^{(2)}$ & 2,40 & 0,20 \\
\hline CMAP $\left(m g g^{-1}\right)^{(3)}$ & 800 & 600 \\
\hline Areia grossa $\left(\mathrm{g} \mathrm{kg}^{-1}\right)^{(4)}$ & 80 & 610 \\
\hline Areia fina $\left(\mathrm{g} \mathrm{kg}^{-1}\right)^{(4)}$ & 170 & 160 \\
\hline Silte $\left(\mathrm{g} \mathrm{kg}^{-1}\right)^{(4)}$ & 140 & 40 \\
\hline Argila $\left(\mathrm{g} \mathrm{kg}^{-1}\right)^{(4)}$ & 610 & 190 \\
\hline Umidade equivalente $\left(\mathrm{kg} \mathrm{dm}^{-3}\right)$ & 329 & 91 \\
\hline Capacidade de campo $\left(\mathrm{m} \mathrm{m}^{-3}\right)^{(5)}$ & 413 & 142 \\
\hline Densidade do solo $\left(\mathrm{kg} \mathrm{dm}^{-3}\right)^{(6)}$ & 0,90 & 1,30 \\
\hline Densidade de partículas $\left(\mathrm{kg} \mathrm{dm}^{-3}\right)^{(7)}$ & 2,53 & 2,65 \\
\hline
\end{tabular}

(1) Extrator Mehlich-1. ${ }^{(2)}$ Extrator KCl 1 mol L ${ }^{-1}{ }^{(3)}$ Método da pipeta. ${ }^{(4)}$ Capacidade máxima de adsorção de fósforo. ${ }^{(5)}$ Método da coluna (Fernandes, 1967). ${ }^{(6)}$ Método do anel volumétrico.

(7) Método do balão volumétrico. doses de P) para cada solo, no delineamento experimental inteiramente casualizado, com quatro repetições. Para o LV, utilizaram-se as densidades de 0,90 (densidade da amostra de solo - Ds), 1,10 (Ds + 20\%) e 1,30 (Ds + $40 \%) \mathrm{kg} \mathrm{dm}^{-3}$ e doses de P de 0, 100, 200 400 e $800 \mathrm{mg} \mathrm{dm}^{-3}$; e para o LVA, 1,30 (densidade da amostra de solo - Ds), 1,50 (Ds + $15 \%)$ e 1,70 (Ds + $30 \%) \mathrm{kg} \mathrm{dm}^{-3}$ e doses de $\mathrm{P}$ de $0,75,150,300$ e $600 \mathrm{mg} \mathrm{dm}^{-3}$. As doses de $\mathrm{P}$ corresponderam, respectivamente, a $0,12,5,25,50$ e $100 \%$ da capacidade máxima de adsorção de $\mathrm{P}$ desses solos (Quadro 1). Foram usados vasos plásticos com capacidade de 1,8 L, com o volume dos solos ocupando 1,6 $\mathrm{dm}^{3}$, nos quais foram cultivadas três plantas por espécie.

Para o plantio da soja, porções suficientes de ambos os solos receberam correção da acidez com $\mathrm{CaCO}_{3}+$ $\mathrm{MgCO}_{3}$ p.a., na relação equivalente Ca:Mg de 4:1, visando elevar o $\mathrm{pH}$ a 6,0 , cujas doses foram estabelecidas de acordo com curvas de incubação. Após homogeneização, os solos permaneceram incubados por 30 dias com umidade elevada à capacidade de campo. Quanto ao plantio do eucalipto, os solos não receberam correção, mas apenas uma dose de $\mathrm{MgCl}_{2}$ $6 \mathrm{H}_{2} 0$, suficiente para elevar o $\mathrm{Mg}$ a $0,4 \mathrm{cmol}_{\mathrm{c}} \mathrm{dm}^{-3}$, aplicada junto com a adubação básica.

Para ambos os experimentos, as porções de cada solo assim estabelecidas receberam as doses de P referentes aos tratamentos e uma adubação básica correspondente a: $100 \mathrm{mg}$ de $\mathrm{N}, 150 \mathrm{mg}$ de $\mathrm{K}, 40 \mathrm{mg}$ de $\mathrm{S}, 0,82 \mathrm{mg}$ de $\mathrm{B}$ e 4,0 $\mathrm{mg}$ de $\mathrm{Zn}$, por $\mathrm{dm}^{3}$ de solo. Utilizaram-se como fontes dos nutrientes os seguintes reagentes p.a.: $\mathrm{KNO}_{3}, \mathrm{NH}_{4} \mathrm{NO}_{3},\left(\mathrm{NH}_{4}\right)_{2} \mathrm{SO}_{4}$, $\mathrm{KH}_{2} \mathrm{PO}_{4}, \mathrm{NH}_{4} \mathrm{H}_{2} \mathrm{PO}_{4}, \mathrm{H}_{3} \mathrm{BO}_{3}$ e $\mathrm{ZnSO}_{4} .7 \mathrm{H}_{2} 0$, aplicados em solução. Na dose mais elevada de $\mathrm{P}$ em cada solo, foi usado também, como fonte de $\mathrm{P}$, superfosfato triplo (ST) comercial ( $\mathrm{P}=19,74 \%$ e $\mathrm{Ca}=13,75 \%$ ), aplicado na forma de pó, correspondendo a 2,43 e 3,24 g por vaso, respectivamente, nos solos LV e LVA. O Ca presente no ST foi compensado, nas demais doses de $\mathrm{P}$, pela aplicação de $\mathrm{CaCl}_{2} \cdot 2 \mathrm{H}_{2} \mathrm{O}$ em solução. Essas porções dos solos foram incubadas em sacos plásticos por 20 dias, com a umidade elevada à capacidade de campo. Decorrido esse período, os solos foram novamente secos, peneirados (4 mm de malha) e os níveis de densidade obtidos colocando-se camadas sucessivas de solo de aproximadamente $3,0 \mathrm{~cm}$ de espessura, sobre as quais exerceu-se a pressão suficiente por meio de êmbolo, para que o peso do solo calculado para cada nível de densidade ocupasse o volume de $1,6 \mathrm{dm}^{3}$ no vaso.

Os dois experimentos, o de soja e o de eucalipto, foram conduzidos simultaneamente, mantendo-se a umidade dos solos a $80 \%$ do volume total de poros (Freire et al., 1980) por meio de pesagens diárias dos vasos e adição de água destilada para repor a água evapotranspirada.

Para a soja, que não recebeu inoculação, foram aplicados, aos 25 dias após a semeadura, $25 \mathrm{mg} \mathrm{dm}^{-3}$ de $\mathrm{N}$ na forma de $\left(\mathrm{NH}_{4}\right)_{2} \mathrm{SO}_{4}$. Aos 40 dias após a semeadura, procedeu-se ao corte das plantas, 
separando-se parte aérea e raízes. Para o eucalipto, foram aplicados, aos 55 e 70 dias, $25 \mathrm{mg} \mathrm{dm}^{-3}$ de $\mathrm{N}$ na forma de $\left(\mathrm{NH}_{4}\right)_{2} \mathrm{SO}_{4}$. Aos 80 dias após a semeadura, avaliou-se a altura das plantas e procedeuse ao corte delas, separando-se parte aérea e raízes. A parte aérea e as raízes de ambas as espécies, após a lavagem com água destilada, foram secas em estufa com circulação forçada de ar a $70^{\circ} \mathrm{C}$ até peso constante, quando foram tomados os pesos da matéria seca. Após trituração em moinho tipo Wiley, as amostras foram submetidas à digestão nítricoperclórica e foi analisado o teor de P (Braga \& Defelipo, 1974). O P acumulado em cada parte da planta foi determinado relacionando-se os teores de $\mathrm{P}$ e a matéria seca produzida. A taxa de recuperação do $\mathrm{P}$ pela planta (em \%) em cada dose aplicada foi calculada pela expressão:

$\mathrm{P}$ recuperado $(\%)=100 \times[(\mathrm{P}$ total acumulado para a dose testada - $\mathrm{P}$ total acumulado para a dose zero)/P aplicado na dose testada]

Análises de variância foram realizadas para a matéria seca da parte aérea (MSPA) e de raízes (MSR), altura do eucalipto e conteúdo de P na MSPA (P-PA) e MSR (P-R), nas duas espécies. Equações de regressão foram ajustadas para essas variáveis em função das doses de $\mathrm{P}$ aplicadas.

\section{RESULTADOS E DISCUSSÃO}

As produções de matéria seca da parte aérea (MSPA) e de raízes (MSR) da soja e do eucalipto, bem como a altura da última espécie, foram influenciadas $(p<0,01)$ pelos solos, densidades de solo e doses de $\mathrm{P}$, com interação entre os fatores (Figuras 1 e 2).

As doses de $\mathrm{P}$ promoveram aumentos na MSPA e MSR de ambas as espécies e na altura do eucalipto, embora a magnitude desses aumentos tenha variado substancialmente entre solos e suas densidades. Equações quadráticas foram as que melhor se ajustaram às variáveis de crescimento em resposta às doses de $\mathrm{P}$ (Figuras 1 e 2), exceto a altura do eucalipto no LV para o nível de densidade de $1,30 \mathrm{~kg} \mathrm{dm}^{-3}$, que apresentou ajuste linear (Figura 2e). A faixa de doses de $\mathrm{P}$ utilizadas no trabalho foi suficiente para atingir o ponto de produção máxima para a MSPA e MSR do eucalipto, nos níveis de densidade de 1,30 e 1,50 kg dm ${ }^{-3}$ no LVA (Figura 2b,d). No caso da altura dessa espécie, atingiu-se o ponto de
LV

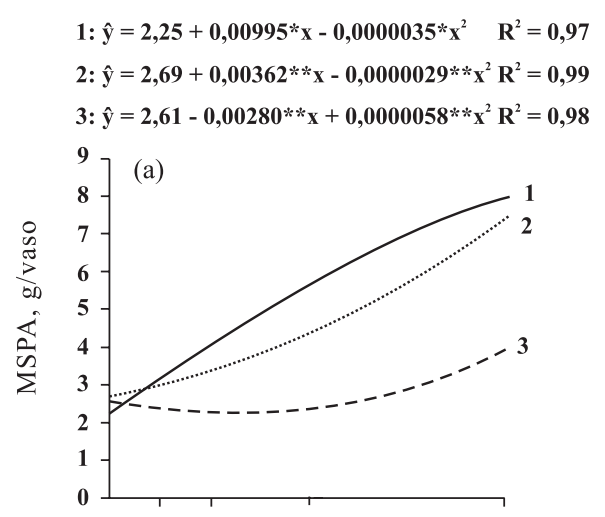

1: $\hat{\mathbf{y}}=0,96+0,00199 * * x-0,0000007 * * x^{2} R^{2}=0,97$

2: $\hat{\mathbf{y}}=1,02+0,00032 * * x+0,0000015 * * x^{2} R^{2}=0,99$

3: $\hat{\mathbf{y}}=0,77-0,00100 * * x+0,0000019 * * x^{2} R^{2}=0,98$

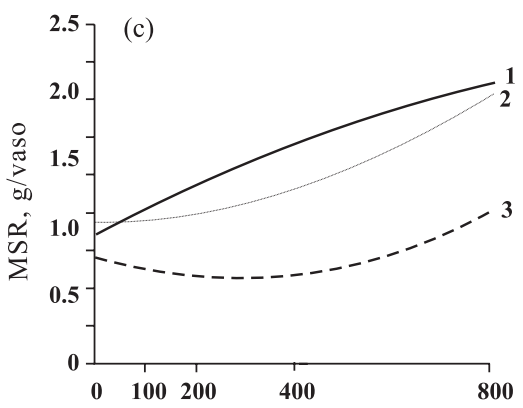

FÓSFORO, $\mathrm{mg} \mathrm{dm}^{-3}$
LVA

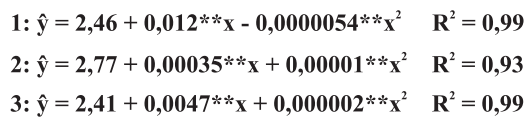

(b)

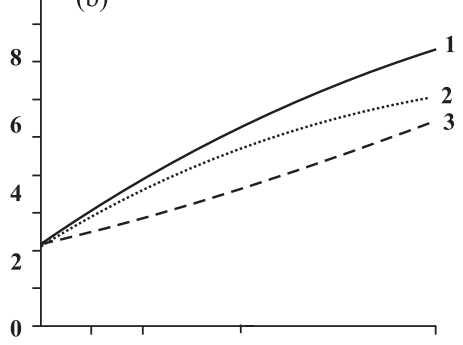

1: $\hat{\mathbf{y}}=0,87+0,0035^{* *} \mathrm{x}-0,0000023 * * \mathrm{x}^{2} \mathbf{R}^{2}=0,99$

2: $\hat{\mathbf{y}}=0,84+0,0016^{* *} \mathrm{x}-0,0000008 * * x^{2} R^{2}=0,98$

3: $\hat{y}=0,69+0,0012 * * x+0,0000004 * * x^{2} R^{2}=0,93$

(d)

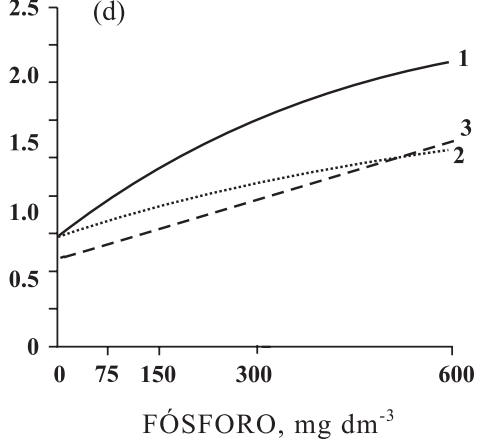

Figura 1. Matéria seca da parte aérea $(a, b)$ e das raízes $(c, d)$ da soja cultivada no LV e LVA em função das doses de fósforo, de acordo com cada densidade (LV: $1=0,90,2=1,10$ e $3=1,30 \mathrm{~kg} \mathrm{dm}^{-3}$; LVA: $1=1,30,2=1,50$ e $\left.3=1,70 \mathrm{~kg} \mathrm{dm}^{-3}\right)\left(* * \mathrm{e}^{*}\right.$ : significativos a 1 e $5 \%$, respectivamente, pelo teste $\left.\mathrm{t}\right)$. 

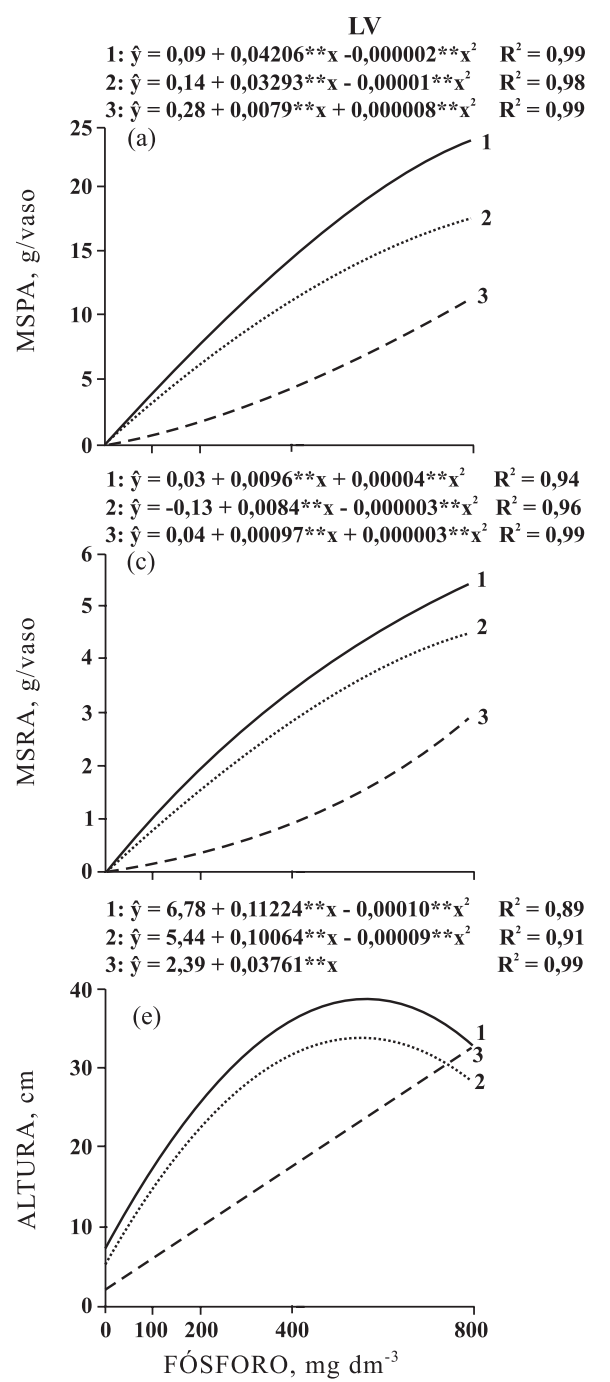

LVA
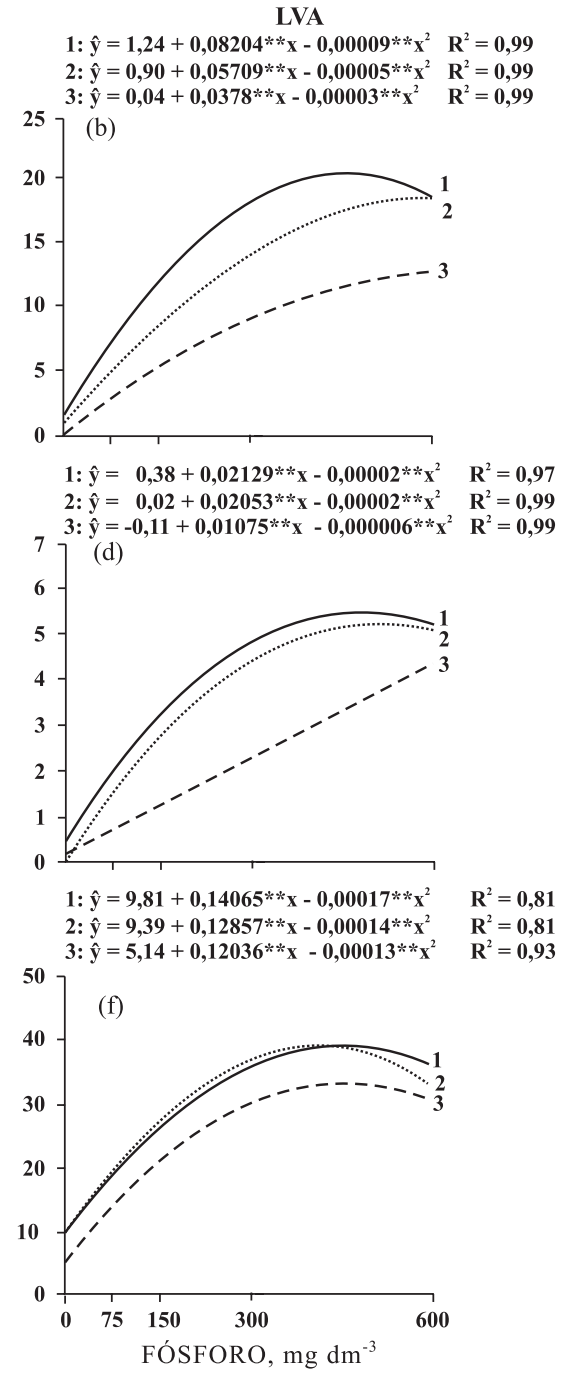

Figura 2. Matéria seca da parte aérea - MSPA - (a, b) e das raízes - MSRA - (c, d) e altura da planta (e, f) do eucalipto cultivado no LV e LVA em função das doses de fósforo, de acordo com cada densidade (LV: $1=0,90,2=1,10$ e $3=1,30 \mathrm{~kg} \mathrm{dm}^{-3}$; LVA: $1=1,30,2=1,50$ e $\left.3=1,70 \mathrm{~kg} \mathrm{dm}^{-3}\right)(* *$ e *: significativos a 1 e $5 \%$, respectivamente, pelo teste $t$ ).

máxima em praticamente todos os solos e níveis de densidade, com exceção do nível de $1,30 \mathrm{~kg} \mathrm{dm}^{-3} \mathrm{no} \mathrm{LV}$, cuja resposta foi linear (Figura 2e, f).

O aumento da densidade dos solos promoveu efeito depressivo no crescimento das espécies em ambos os solos, principalmente na maior densidade: 1,30 e $1,70 \mathrm{~kg} \mathrm{dm}^{-3}$, no $\mathrm{LV}$ e $\mathrm{LVA}$, respectivamente (Figuras 1 e 2). A redução observada na parte aérea da soja foi de $50 \%$ no solo LV e $26 \%$, no LVA; para o eucalipto, esses valores foram de 52 e $32 \%$, respectivamente. Silva et al. (2006) também verificaram redução significativa no crescimento da parte aérea de plantas de soja cultivadas em um LVA na densidade do solo de $1,40 \mathrm{~kg} \mathrm{dm}^{-3}$.

A diminuição do crescimento pela compactação dos solos deveu-se à redução da magnitude de resposta das espécies às doses de $\mathrm{P}$, o que pode ser observado pela inclinação das curvas das figuras 1 e 2 . Considerando-se como máxima a produção de MSPA da soja no LV, no nível de densidade $3\left(1,30 \mathrm{~kg} \mathrm{dm}^{-3}\right)$, aquela obtida na dose de $800 \mathrm{mg} \mathrm{dm}^{-3}$ de $\mathrm{P}$ (Figura 1a), essa mesma produção de MSPA é obtida com a aplicação de apenas 185 e $295 \mathrm{mg} \mathrm{dm}^{-3}$ de $\mathrm{P}$, para os níveis de densidade $1\left(0,90 \mathrm{~kg} \mathrm{dm}^{-3}\right)$ e $2\left(1,10 \mathrm{~kg} \mathrm{dm}^{-3}\right)$, respectivamente. Da mesma forma para o eucalipto, a mesma produção de MSPA é obtida no LV (Figura 2a) pela aplicação das doses de 330, 415 e $800 \mathrm{mg} \mathrm{dm}^{-3}$ de $\mathrm{P}$, quando se variam as densidades do solo de $0,90,1,10$ e $1,30 \mathrm{~kg} \mathrm{dm}^{-3}$, respectivamente. Efeitos semelhantes podem ser observados para todas as variáveis de crescimento estudadas, em ambos os solos e espécies. Assim, o aumento da densidade dos solos, além de reduzir o crescimento das plantas, reduziu também, drasticamente, a eficiência da adubação fosfatada. 
A relação parte aérea/raízes (dados não apresentados) indica em qual parte da planta os fatores estudados exerceram maior efeito na produção de matéria seca das espécies. Embora não houvesse tendência bem definida dentro das doses de $\mathrm{P}$ aplicadas, de maneira geral, o aumento da densidade, proporcionalmente, reduziu mais a matéria seca de raízes do que de parte aérea da soja, em ambos os solos; para o eucalipto, os valores observados foram menos consis- tentes (Figuras 1 e 2). Beutler \& Centurion (2003, 2004) também observaram maior redução na produção de MSR ao avaliarem o efeito da compactação do solo na produção de soja.

O P acumulado na parte aérea (P-PA) e nas raízes $(\mathrm{P}-\mathrm{R})$ das espécies foi influenciado $(\mathrm{p}<0,01)$ pelos solos, pela densidade de solo e pelas doses de $\mathrm{P}$, com interação entre os fatores (Figura 3).
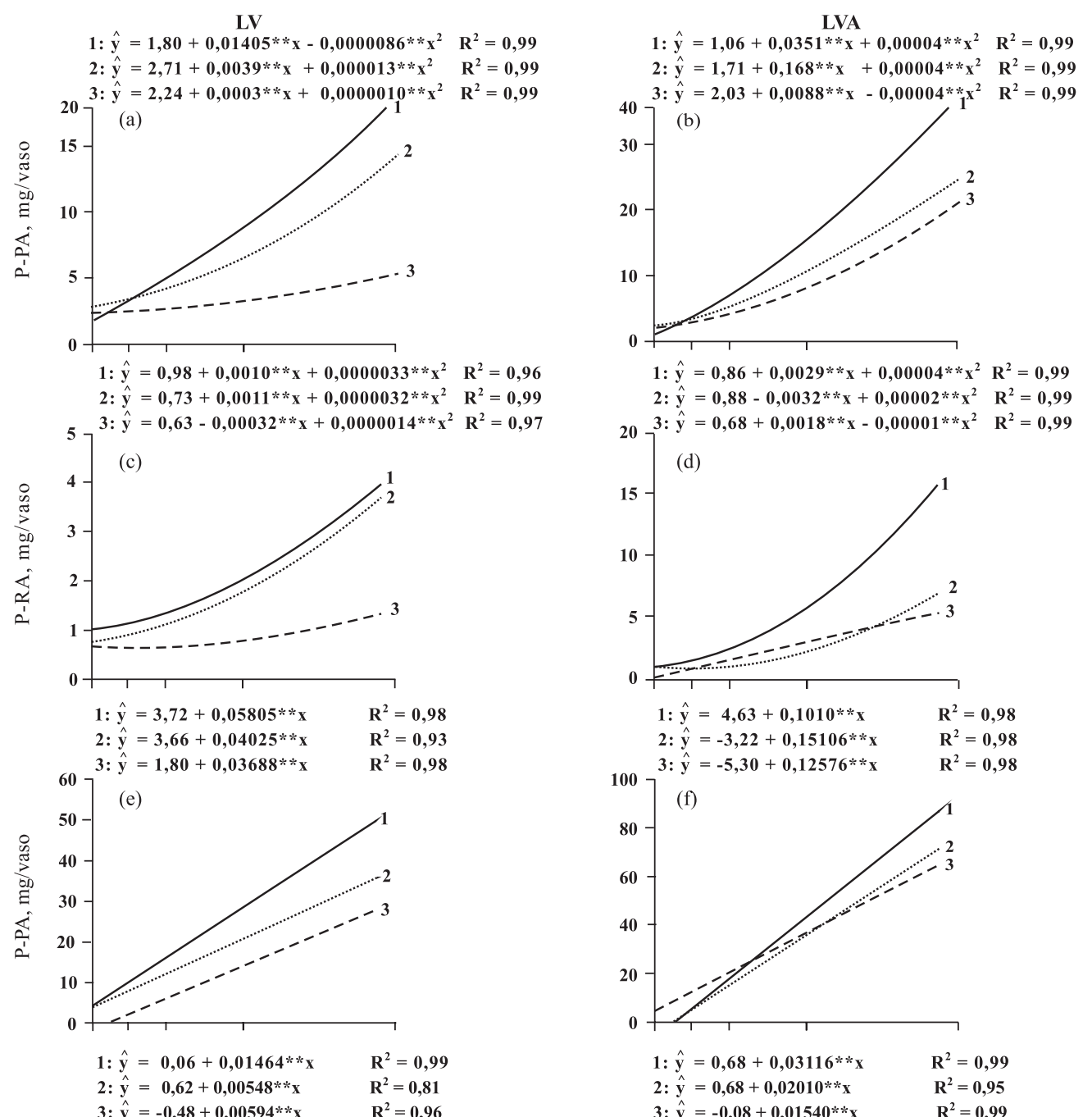

1: $\hat{\mathbf{y}}=0,86+0,0029 * * x+0,00004 * * x^{2} R^{2}=0,99$ 2: $\hat{\mathbf{y}}=0,88-0,0032 * * x+0,00002 * * x^{2} \quad R^{2}=0,99$
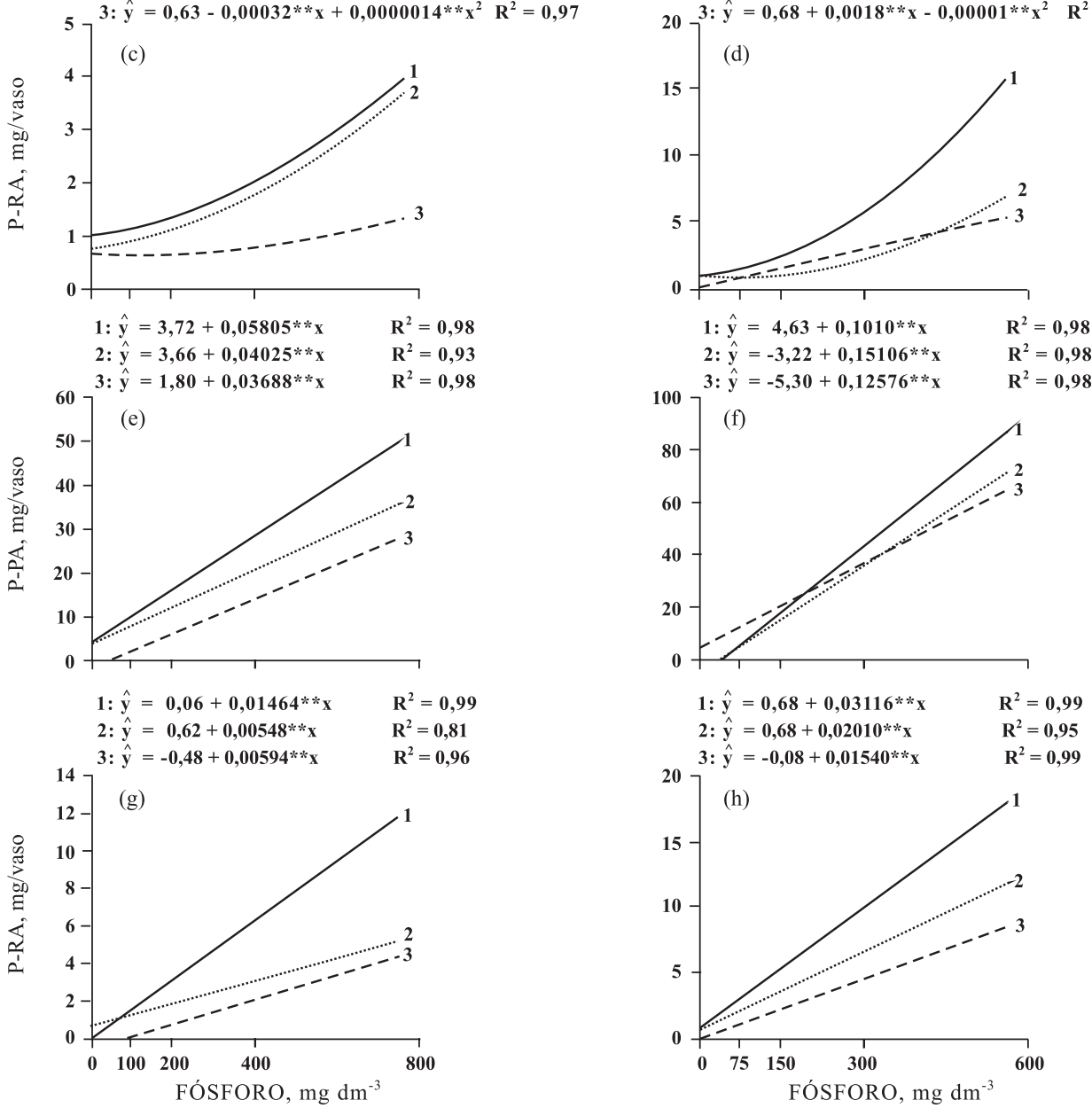

Figura 3. Fósforo acumulado na parte aérea - P-PA - (a, b) e nas raízes - P-RA - (c, d) da soja e na parte aérea $(e, f)$ e nas raízes $(g, h)$ do eucalipto cultivados no LV e LVA em função das doses de fósforo, de acordo com cada densidade (LV: $1=0,90,2=1,10$ e $3=1,30 \mathrm{~kg} \mathrm{dm}^{-3}$; LVA: $1=1,30,2=1,50$ e $\left.3=1,70 \mathrm{~kg} \mathrm{dm}^{-3}\right)\left(* * \mathrm{e}^{*}\right.$ : significativos a 1 e $5 \%$, respectivamente, pelo teste $t$ ). 
Quadro 2. Recuperação de fósforo pela soja e eucalipto cultivados no LV e LVA em função dos níveis de densidade do solo e doses de fósforo

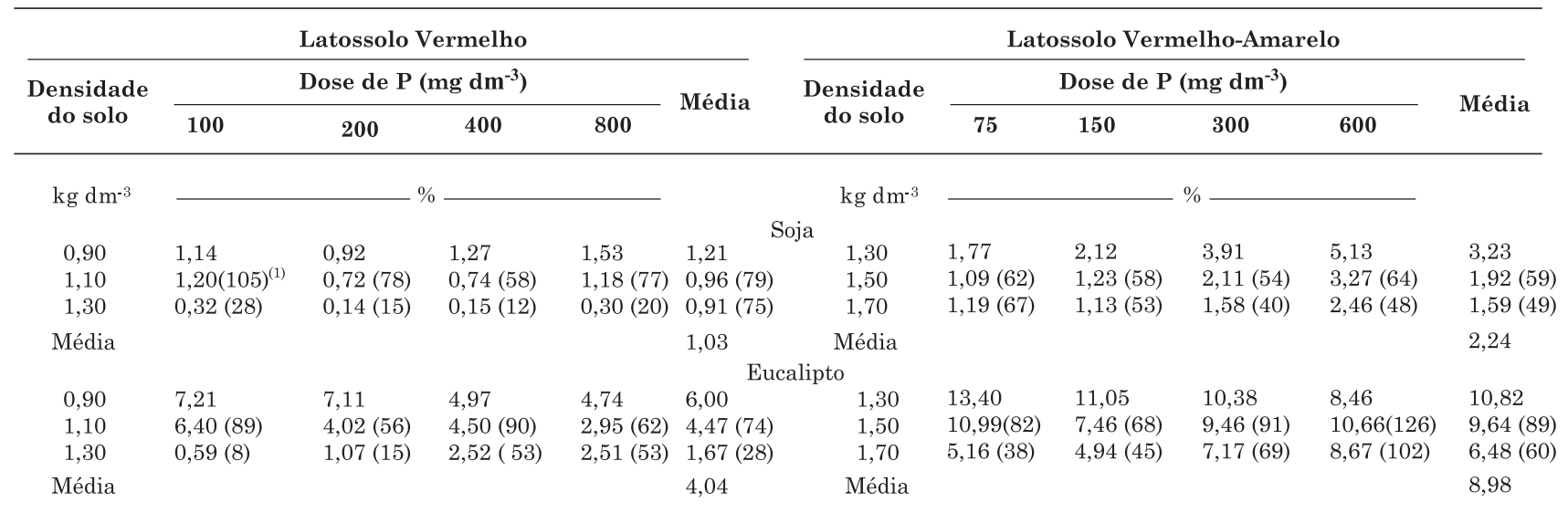

(1) Os números entre parênteses representam, para cada variável, dentro de cada dose e média das doses de P, a recuperação relativa desse nutriente nos maiores níveis de densidade em relação ao menor nível, que recebeu valor 100.

De modo geral, os efeitos dos fatores estudados sobre o acúmulo de P nas espécies seguiram o mesmo comportamento daqueles observados para a produção de matéria seca das plantas, dada a relação direta entre as duas variáveis. As quantidades de $\mathrm{P}$ acumulado na parte aérea e nas raízes pela soja e pelo eucalipto (Figura 3) aumentaram com as doses de P aplicadas, embora a magnitude desses aumentos tenha variado substancialmente entre espécies, solos e suas densidades. Para a soja, o acúmulo de $\mathrm{P}$ em função de suas doses seguiu, para todos os níveis de densidade, em ambos os solos, um comportamento quadrático, passando por um mínimo; para o eucalipto, esse efeito foi linear (Figura 3).

A restrição à aquisição do $\mathrm{P}$ pelas plantas, como consequência do aumento da densidade do solo, pode ser confirmada pelo acúmulo de P na MSPA da soja cultivada no LV (Figura 3a), ou seja, o mesmo acúmulo de $\mathrm{P}$ observado no maior nível de densidade $\left(1,30 \mathrm{~kg} \mathrm{dm}^{-3}\right)$ e na maior dose de $\mathrm{P}\left(800 \mathrm{mg} \mathrm{kg}^{-1}\right)$ pode ser obtido nos níveis $1\left(0,90 \mathrm{~kg} \mathrm{dm}^{-3}\right)$ e $2\left(1,10 \mathrm{~kg} \mathrm{dm}^{-3}\right)$ com a aplicação de apenas 205 e $300 \mathrm{mg} \mathrm{kg}^{-1}$ de P, respectivamente. Assim, o aumento da densidade, reduzindo a absorção e acumulação de $\mathrm{P}$, diminui a recuperação pelas plantas do $\mathrm{P}$ aplicado (Quadro 2). De maneira geral, a recuperação do $\mathrm{P}$ foi baixa, situando-se em valores inferiores a 13,5 \%. Muniz et al. (1985) verificaram que a taxa de recuperação do $P$ aplicado por plantas de soja correlacionou-se inversamente com a capacidade-tampão de $\mathrm{P}$ dos solos, ou seja, para a mesma quantidade de $\mathrm{P}$ absorvida, é necessário maior quantidade de $\mathrm{P}$ em solo com maior capacidade-tampão, como observado no mais argiloso (LV). O eucalipto mostrou-se mais eficiente do que a soja nessa recuperação, e os maiores valores foram observados para o solo LVA. Esse fato pode ser justificado pela maior produção de MSR pelo eucalipto, possivelmente com maior exploração do volume do solo, criando uma situação de maior dreno do nutriente. As maiores inclinações das curvas e retas observadas para o LVA em relação ao LV (Figura 3) mostram que ambas as espécies acumularam maiores quantidades de $\mathrm{P}$ por unidade do nutriente aplicado, o que levou a um maior aproveitamento do $\mathrm{P}$ aplicado no LVA.

A menor absorção de $\mathrm{P}$ pelas plantas como consequência do aumento da densidade dos solos tem na diminuição do fluxo difusivo de $\mathrm{P}$ nos solos a causa provável de menor crescimento das plantas. Resultados semelhantes estão disponíveis na literatura sobre o assunto (Novais et al., 2007).

\section{CONCLUSÕES}

1. O aumento da densidade dos solos reduziu o crescimento da soja e do eucalipto, cujo efeito foi mais pronunciado no Latossolo Vermelho (mais argiloso) do que no Latossolo Vermelho-Amarelo (menos argiloso), sendo o eucalipto mais alterado do que a soja.

2. O aumento da densidade dos solos reduziu a eficiência da adubação fosfatada, mostrando-se o eucalipto mais eficiente na recuperação do fósforo aplicado aos solos do que a soja.

3. O efeito negativo do aumento da densidade dos solos sobre a produção de matéria seca das plantas, nas menores doses de $\mathrm{P}$, é compensado quando as maiores doses são aplicadas.

\section{LITERATURA CITADA}

BRAGA, J.M. \& DEFELIPO, B.V. Determinação espectrofotométrica de fósforo em extrato de solos e plantas. R. Ceres, 21:73-85, 1974. 
BEUTLER, A.N. \& CENTURION, J.F. Efeito do conteúdo de água e da compactação do solo na produção de soja. Pesq. Agropec. Bras., 38:849-856, 2003.

BEUTLER, A.N. \& CENTURION, J.F. Compactação do solo no desenvolvimento radicular e na produtividade da soja. Pesq. Agropec. Bras., 39:581-588, 2004.

BORGES, E.N.; NOVAIS, R.F.; BARROS, N.F.; COSTA, L.M. \& NEVES, J.C.L. Respostas de mudas de eucalipto a camadas compactadas de solo. R. Árvore, 10:181-195, 1986.

BORGES, E.N.; NOVAIS, R.F.; BARROS, N.F.; REGAZZI, A.J. \& FERNANDES, B. Respostas de variedades de soja à compactação de solo. R. Ceres, 35:553-568, 1987.

CARVALHO JÚNIOR, I.A.; FONTES, L.E.F. \& COSTA, L.M. Modificações causadas pelo uso e a formação de camadas compactadas e/ou adensadas, em um Latossolo VermelhoEscuro textura média na região do Cerrado. R. Bras. Ci. Solo, 22:505-514, 1998.

EMPRESA BRASILEIRA DE PESQUISA AGROPECUÁRIA EMBRAPA. Centro Nacional de Pesquisa de Solos. Manual de métodos de análises de solos. Rio de Janeiro, 1997. 212p.

FERNANDES, B. Retenção e movimento de água no solo. Viçosa, MG, Universidade Federal de Viçosa, 1967. 48p. (Tese de Mestrado)

FLOWERS, M.D. \& LAL, R. Axle load and tillage effects on soil physical properties and soybean grain yield on a mollic ochraqualf in northwest Ohio. Soil Till. Res., 48:21-35, 1998.

FOLONI, J.S.S.; CALONEGO, J.C. \& LIMA, S.L. Efeito da compactação do solo no desenvolvimento aéreo e radicular de cultivares de milho. Pesq. Agropec. Bras., 38:947-953, 2003.

FREDDI, O.S.; CENTURION, J.F.; BEUTLER, A.N.; ARATANI, R.G. \& LEONEL, C.L. Compactação do solo no crescimento radicular e produtividade da cultura do milho. R. Bras. Ci. Solo, 31:627-636, 2007.
FREIRE, J.C.; RIBEIRO, M.A.V.; BAHIA, V.G.; LOPES, A.S. \& AQUINO, L.H. Resposta do milho cultivado em casa de vegetação a níveis de água em solos da região de Lavras (MG). R. Bras. Ci. Solo, 4:4-8, 1980.

MUNIZ, A.S.; NOVAIS, R.F.; BARROS, N.F. \& NEVES, J.C.L. Nível crítico de fósforo na parte aérea da soja como variável do fator capacidade de fósforo do solo. R. Bras. Ci. Solo, 9:237-243, 1985.

NOVAIS, R.F. \& SMYTH, T.J. Fósforo em solo e planta em condições tropicais. Viçosa, MG, Universidade Federal de Viçosa, 1999. 399p.

NOVAIS, R.F.; SMYTH, T.J. \& NUNES, F.N. Fósforo. In: NOVAIS, R.F.; ALVAREZ V., V.H.; BARROS, N.F.; FONTES, R.L.F. \& CANTARUTTI, R.B., eds. Fertilidade do solo. Viçosa, MG, Sociedade Brasileira de Ciência do Solo, 2007. p.471-550.

NYE, P.H. Diffusion of ions and uncharged solutes in soils and soil clays. Adv. Agron., 31:225-272, 1979.

ROSOLEM, C.A.; ALMEIDA, A.C.S. \& SACRAMENTO, L.V.S. Sistema radicular e nutrição da soja em função da compactação do solo. Bragantia, 53:259-266, 1994.

RUIZ, H.A.; FERNANDES, B.; NOVAIS, R.F. \& ALVAREZ V., V.H. Efeito da umidade do solo sobre o volume e o conteúdo de fósforo no exsudato xilemático de soja. R. Bras. Ci. Solo, 12:39-42, 1988.

SILVA, G.J.; MAIA, J.C.S. \& BIANCHINI, A. Crescimento da parte aérea de plantas cultivadas em vaso, submetidas à irrigação subsuperficial e a diferentes graus de compactação de um Latossolo Vermelho-Escuro distrófico. R. Bras. Ci. Solo, 30:31-40, 2006.

TAVARES FILHO, J.; BARBOSA, G.M.; GUIMARÃES, M.F. \& FONSECA, I.C.B. Resistência à penetração e desenvolvimento do sistema radicular do milho (Zea mays) sob diferentes sistemas de manejo em um Latossolo Roxo. R. Bras. Ci. Solo, 25: 725-730, 2001.

VILLANI, E.M.A.; NOVAIS, R.F.; BARROS, N.F.; FONTES, L.E.F. \& NEVES, J.C.L. Difusão de fósforo em solos com diferentes texturas e níveis de umidade. R. Bras. Ci. Solo, 17:343-347, 1993 